\title{
Collaborative governance in the Quebec Cancer Network: a realist evaluation of emerging mechanisms of institutionalization, multi-level governance, and value creation using a longitudinal multiple case study design
}

Dominique Tremblay ${ }^{1,2^{*}}$ (D) Nassera Touati ${ }^{2,3}$, Thomas Poder ${ }^{4,5,6,7}$, Helen-Maria Vasiliadis ${ }^{1,2}$, Karine Bilodeau ${ }^{8}$, Djamal Berbiche ${ }^{2}$, Jean-Louis Denis ${ }^{9,10,11,12}$, Marie-Pascale Pomey 9,10,12, Johanne Hébert ${ }^{13,14,15,16}$, Geneviève Roch ${ }^{14,15,17,18,19}$, Catherine Prady ${ }^{1,2,20,21}$ and Lise Lévesque ${ }^{1,2}$

\begin{abstract}
Background: People living with and beyond cancer (PLC) receive various forms of specialty care at different locations and many interventions concurrently or over time. They are affected by the operation of professional and organizational silos. This results in undue delays in access, unmet needs, sub-optimal care experiences and clinical outcomes, and human and financial costs for PLCs and healthcare systems.

National cancer control programs advocate organizing in a network to coordinate actions, solve fragmentation problems, and thus improve clinical outcomes and care experiences for every dollar invested. The variable outcomes of such networks and factors explaining them have been documented. Governance is the "missing link" for understanding outcomes. Governance refers to the coordination of collective action by a body in a position of authority in pursuit of a common goal. The Quebec Cancer Network (QCN) offers the opportunity to study in a natural environment how, why, by whom, for whom, and under what conditions collaborative governance contributes to practices that produce value-added outcomes for PLCs, healthcare providers, and the healthcare system.

(Continued on next page)
\end{abstract}

\footnotetext{
* Correspondence: dominique.tremblay2@usherbrooke.ca

${ }^{1}$ Faculté de médecine et des sciences de la santé, Campus de Longueuil Université de Sherbrooke, 150 Place Charles-Le Moyne, Longueuil, Québec J4K 0A8, Canada

${ }^{2}$ Centre de recherche Charles-Le Moyne - Saguenay-Lac-Saint-Jean sur les innovations en santé (CR-CSIS), Centre intégré de santé et de services sociaux de la Montérégie-Centre, 150 Place Charles-Le Moyne, Longueuil, Québec J4K 0A8, Canada

Full list of author information is available at the end of the article
}

(c) The Author(s). 2019 Open Access This article is distributed under the terms of the Creative Commons Attribution 4.0 International License (http://creativecommons.org/licenses/by/4.0/), which permits unrestricted use, distribution, and reproduction in any medium, provided you give appropriate credit to the original author(s) and the source, provide a link to the Creative Commons license, and indicate if changes were made. The Creative Commons Public Domain Dedication waiver (http://creativecommons.org/publicdomain/zero/1.0/) applies to the data made available in this article, unless otherwise stated. 


\begin{abstract}
(Continued from previous page)
Methods/design: The study design consists of a longitudinal case study, with multiple nested cases (4 local networks nested in the QCN), mobilizing qualitative and quantitative data and mixed data from various sources and collected using different methods, using the realist evaluation approach. Qualitative data will be used for a thematic analysis of collaborative governance. Quantitative data from validated questionnaires will be analyzed to measure relational coordination and teamwork, care experience, clinical outcomes, and health-related health-related quality of life, as well as a cost analysis of service utilization. Associations between context, governance mechanisms, and outcomes will be sought. Robust data will be produced to support decision-makers to guide network governance towards optimized clinical outcomes and the reduction of the economic toxicity of cancer for PLCs and health systems.
\end{abstract}

Keywords: Network governance, Patient care experience, Resource utilization, Cost analysis, Longitudinal case study, Realist evaluation, Organizational research

\section{Background}

People living with and beyond cancer (PLC) need timely access to proven, coordinated, continuous care focused on their values and preferences [1-3]. They must receive care and services, concurrently or over time, from multiple professionals and practitioners working in various locations (ambulatory oncology clinics, hospitalization units, doctors' offices, CLSCs, homes, palliative care residences) $[4,5]$. In order to meet these needs, it is imperative to avoid operating in silos, which results in unwanted outcomes, as has been widely documented $[2,6]$. International experience [7, 8], the experience in Quebec (Canada) [9], as well as our previous work [10-12] show that, although structural levers are necessary to integrate care and services, they do not suffice to optimize the supply of services to PLCs. This is why providing safe and high-quality care and services requires a shift from a logic based on autonomy and independence to a logic of interdependence where teamwork allows for the exchange of knowledge and expertise [13] and for shared leadership that goes beyond the invisible walls between professions and organizations, and that includes PLCs $[14,15]$. Organizing in the form of an integrated network centred on PLCs is therefore a logical choice.

\section{A network to integrate care}

A network refers to a form of organization of collective action where groups of actors with their own and often competing goals, values, needs, and forms of representation must rally around a common goal [4]. In general, a network is defined as "multiple organizations which are tied by some form of structural interdependence in which one unit is not the subordinate of others [...] that coordinate their joint activities through different types of peer-to-peer relations" ([4] p. 529).

Integrated network operation has been a dominant theme in national cancer control programs in several countries for more than two decades [2, 16-22]. Cancer networks are intended to be a solution to the classic fragmented service offering model, which is not optimal to meet the needs and expectations of PLCs. In recognizing the interdependence inherent in providing cancer care [13], networks are integrative tools to rebuild practices around new relationships essential to the quality and safety of care, thereby reducing the burden of disease.

Studies on health networks have focused mainly on mandated networks, i.e. networks with a political mandate. The multiple factors influencing their implementation are well documented [4, 23-25]: coordination mechanisms and tools, size of the network, internal stability), operational characteristics (manager competence, knowledge sharing, development of innovation capacities, mobilization of professionals, member participation and commitment) and contextual characteristics (stability of the health system, access to human, financial, informational resources, cohesion, community support). Certain studies have concluded that professional commitment, legitimacy leadership, and trust are determinants of network performance and sustainability [24, 26, 27].

Some benefits of integrated network operation have been reported [28]. The most robust evidence comes from networks for elderly persons. Positive outcomes have been demonstrated in terms of improved functional and cognitive status [29-33], access to social support, and satisfaction [30]. However, the benefits for healthcare systems are mixed. Some studies have found a decrease in hospitalizations and readmissions [34, 35], length of hospital stay [36], and use of emergency services [34]. While some studies have reported a decrease in hospital costs, others have concluded that networks have not reduced costs [37].

On the other hand, unanticipated or unwanted results of mandated networks have also been reported. There are always gaps between a network "prescribed" at the political level and one that is taking shape on the ground. Networking is a major change that is not easily imposed, with professionals having a central role in transforming the provision of care [38] and the power to resist the prescription openly or passively [39]. As a result, anticipated 
benefits of networks are not materializing as expected. These differences can be explained by several individual, organizational, and contextual factors whose influence varies according to the type of network, its stage of development, or its degree of integration [4, 7, 40-44].

For example, Addicott et al. have shown that formalization of the roles of actors (individuals or organizations) in networks could weaken existing informal links before new linking mechanisms can be put in place. This results in dilution of clinical expertise due to dismantling of informal mechanisms for exchange of information and knowledge [45]. This same study also showed that the negative perception of the presence of an external control body in the network undermined managers' efforts to support clinicians' ownership of network practices. One of the few studies in the field of cancer care, conducted in the United Kingdom [45], showed how a governance body at the political level focused on organizational restructuring and performance rather than knowledge sharing can have an undesirable impact on the implementation of a network. Others have reported an increase in the use of emergency services due to increased patient vigilance in the event of a deterioration in their state of health and the lack of alternatives [36]. Yet others have found that the resources and efforts devoted to setting up clinical networks generate costs that do not necessarily translate into concrete benefits for service users [40].

\section{From prescribed network to actual network}

The transition from the "prescribed" network (following a national cancer plan) to an "actual" network (in the field) is particularly challenging. Clinicians' professional practices are based on their autonomy, expertise, identity, and relationships with different stakeholders [46], while clinical decision-making is rooted in the uniqueness of a PLC's trajectory, which poses challenges for collective action [47]. For managers, being in a network requires significant relational work between professionals and organizations [48] to ensure coordination of care provision in and between different teams, in a system where reforms are affecting all dimensions of cancer care provision [1]. Updating to new approaches that have been conceived at the political level but need to be implemented at the clinical level represents a test of managerial leadership. The challenge is all the greater since the benefits of integrated network operation manifest as small changes in practices and small gains that can take up to 20 years to become visible [49]. However, if professionals do not see the benefits of their transformation efforts, they are likely to be reluctant to change their practice in favour of networking. For policy makers, who are more familiar with hierarchical or "topdown" functioning, networking requires them to learn a new way of making decisions that is shared with nongovernmental actors (clinicians, managers, PLCs). As for PLCs, our work shows that they associate their unmet needs in part with the fragmented organization of care and services, and the notion of a network can be abstract for them $[50,51]$.

\section{From network governance to collaborative governance}

Converging evidence points to the importance of understanding governance mechanisms as factors influencing the evolution of networks and their effectiveness [41]. Governance is increasingly recognized as the "missing link" for understanding networks and their outcomes [52], particularly in the health sector [11, 41, 53-55]. Governance is a relatively new, multi-dimensional concept, lacking a consensus definition [56]. Overall, governance refers to the coordination of collective action by an entity in a position of authority [57]. Effective governance requires the efforts of multiple actors to coordinate with each other by mobilizing different operational rules and strategies to achieve the objectives of a network [58, 59]. A thorough understanding of the mechanisms by which networks achieve their outcomes is necessary to improve cancer management and optimize the use of resources invested in networking. In this case, a better consideration of governance dynamics to support the transformation of practices in favour of a high-quality, affordable, and PLCfocused service offer is promising $[41,53,56,58,60,61]$.

Network governance, according to Provan's foundational work, can be conceptualized in two forms: shared governance and centralized governance [23]. Shared governance is the most flexible and least hierarchical form, where the different partners share decision-making power and interact informally. Centralized governance is provided by a lead organization that assumes the lead role due to its central position in providing services to clients and its authority over the distribution of resources [23]. In a literature review, Turrini et al. concluded that the presence of a coordinating body exercising external control was positively associated with the ability to achieve the objectives pursued by a network [4]. A study by Denis et al. showed the positive impact of consolidating a strong central authority within the network when establishing health and social services centres in Quebec [62].

Without denying the contribution of a strong central body, whether internal or external to the network, the plurality of decision-making forums in knowledge-based professional organizations calls for collaborative governance (CG) of networks to overcome barriers to operating in professional and organizational "silos", which are detrimental since they increase the risk of adverse events related to coordination dysfunctions in the healthcare system [63]. Among the many definitions of CG, the one that we believe is most useful in the context of cancer 
networks is as follows: "the processes and structures of public policy decision making and management that engage people constructively across the boundaries of public agencies, levels of government, and/or the public, private and civic spheres in order to carry out a public purpose that could not otherwise be accomplished" [64].

Although CG offers a promising solution, very little work has been done to provide a thorough understanding of the dynamics specific to CG in cancer control. Considering the unprecedented health services reforms conducted not only in Quebec, but in most industrialized countries $[1,63,65,66]$, gaining this understanding is of the utmost importance. Although there are different interpretive frameworks for governance, most are based on theoretical inferences $[55,64]$ that need to be empirically tested. Aside from the work we are doing on the functions of governance [67], we have not identified any studies that could guide the collaboration of multi-level governance actors in addressing what some jurisdictions call the "cancer crisis" [65]. The present study will thus contribute to addressing the need to identify which governance models are most useful and in which context, and to provide examples of best practices to support decision-making confronted with service fragmentation issues [54].

\section{Empirical context}

Integrated network operations is one of the key elements of the national cancer control program (Programme Québécois de Lutte Contre le Cancer) [2], which lays the foundations for the governance of the Quebec Cancer Network (QCN) to deal with the complexity of care provision [68] (p. 36) while optimizing the use of resources [68] (p. 37). The QCN is a "network of networks where the organization of direct and associative links are both formal and informal. The provincial cancer plan reflects a desire to promote and support local initiatives for networking. To do this, it is necessary to rethink network governance by taking into account clinical and human issues to encourage and equip the capacity to act together (collaboration, coordination). Indeed, the implementation of the $\mathrm{QCN}$ poses challenges related to professional issues [69, 70], clinical and bureaucratic routines that create an "iron cage" around practices [71]. Thus, the QCN, a provincial network of local and regional networks, is a typical example where multiple actors (PLCs, clinicians, managers, politicians) with different motivations and acting at different levels of the health system (clinical, organizational, political) must coordinate with each other [72]. As with other clinical client networks, some benefits are observed, but the results are not yet as good as expected [28]. Considering the resources and efforts devoted to governance in the $\mathrm{QCN}$, it is imperative to better understand its mechanisms and implications at the clinical, organizational, political, and economic levels. In addition, the current state of knowledge calls for a better understanding of the outcomes these factors produce for patients [10,67].

The present study builds upon this research [10, 67] and aims to provide an in-depth analysis of how, why, by whom, for whom, and under what conditions CG in a cancer network contributes to outcomes that have added value for PLCs, providers, and the healthcare system. GC is approached as an innovative intervention with clinical, organizational, and political components that mobilize multiple QCN actors acting at different levels of PLC care delivery. Our working hypotheses are that GC in a cancer network is associated with 1) a more positive perception of the PLC care experience; 2) a more positive perception of health-related quality of life; and 3) clinical benefits. Given the state of knowledge about costs, we adopt a more exploratory approach in assessing whether the degree of GC is associated with cost changes.

Our approach uses as an empirical example the provision of care and services to persons living with and beyond cancer (PLC) in the Quebec Cancer Network (QCN). More specifically, the objectives of the study are to: 1) Identify the critical contextual factors that promote or hinder GC at the clinical, management, and policy levels; 2) Explain how and why CG is activated to materially evolve a cancer network; and 3) Compare the outcomes of network CG on: 3a) care experience, 3b) clinical outcomes, 3c) health-related quality of life, and $3 \mathrm{~d})$ costs associated with the use of care and services.

The objectives call for a formative evaluation of CG in the context of hybrid networks such as the QCN - a contemporary phenomenon taking shape in a natural environment - to assess its benefits, which is consistent with the realist evaluation approach [73]. They also involve deepening the analysis of governance mechanisms by focusing more on the interaction between levels of governance [61] and on the interaction between mechanisms of engagement, motivation of actors, and development of capacities for action. Realist evaluation is increasingly being used to understand complex interventions, of which $\mathrm{GC}$ is a typical example. In this case, the QCN $[68,74]$ offers a unique opportunity to submit theoretical GC frameworks to empirical testing in order to draw useful observations for practice.

\section{Methods/design}

Study design

The study design consists of a longitudinal, multiple nested case study [75] using both qualitative and quantitative approaches. The case study, as a methodological approach, is particularly appropriate when the analysis focuses on the dynamics of interaction between actors 
involved in an intervention in a given context [76]. This design is consistent with realist evaluation [77], which structures our in-depth investigation of the links between CG mechanisms and outcomes (see the study design in Fig. 1). According to realist evaluation, the association between GC contextual factors (C) and mechanisms $(\mathrm{M})$ creates the conditions for the production of outcomes (E). These associations formulated as $\mathrm{C}+\mathrm{M}=$ E make explanatory models for studying the production of outcomes of complex interventions intelligible. Quantitative data collection will be conducted using concurrent mixed methods approaches to complement qualitative data (Objectives 1,2) and measure the outcomes associated with GC (Objective 3) [78].

\section{Settings}

The cases under study are four Centres intégrés de santé et services sociaux (integrated health and social services centres - CISSS, or CIUSSS for those with an academic mandate) that provide care and services to PLCs. These four local cancer networks, embedded within the QCN, are instrumental in understanding CG in the QCN and increase the explanatory power by specifying the meaning that actors give to their GC practices in their context [76]. They have been chosen in a reasoned way for their informative potential and diversity [79] that will allow us to compare the differences and similarities explaining the variations in CG mechanisms and outcomes in different contexts. Their organizational characteristics are described in Table 1.

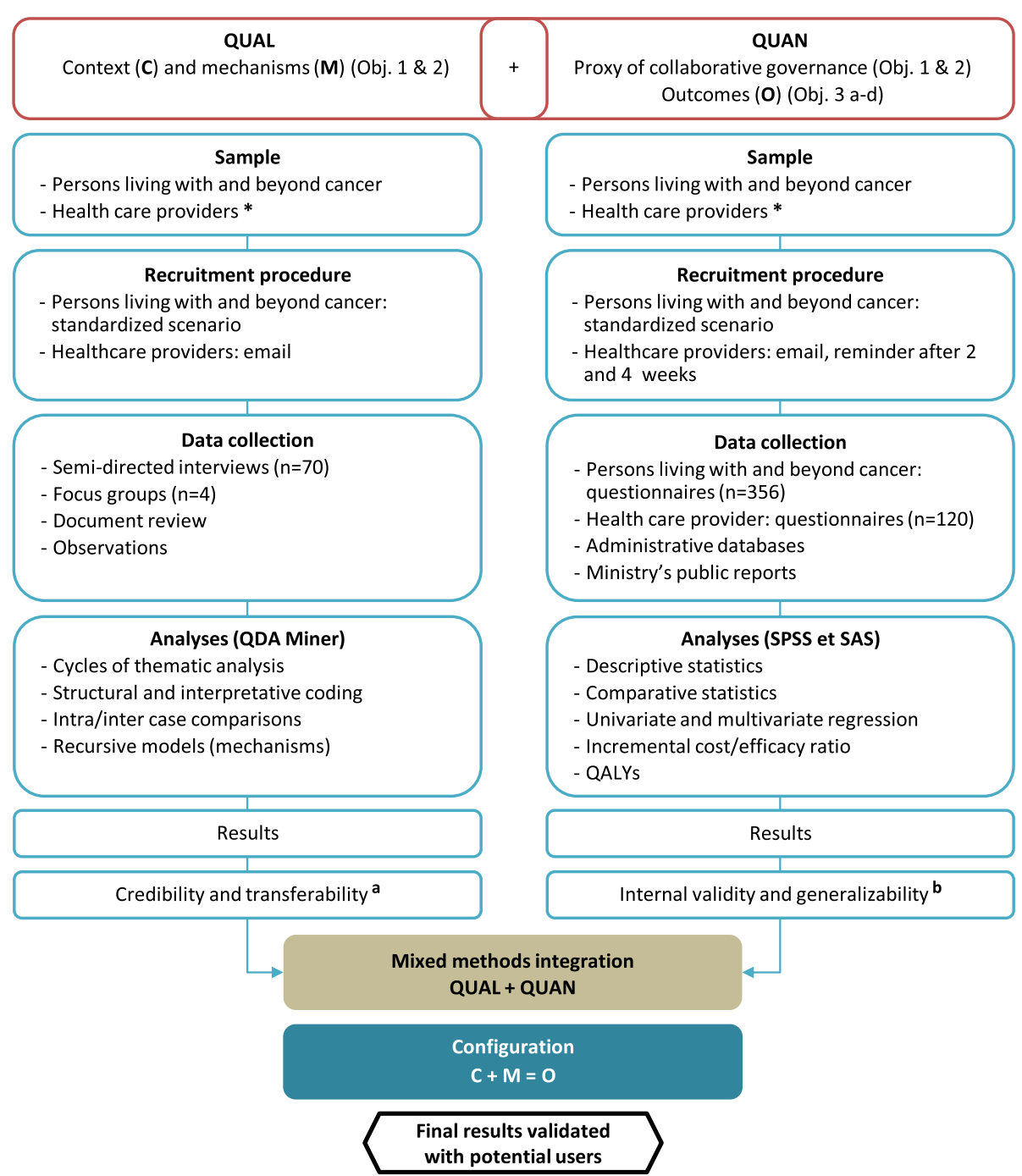

Fig. 1 Study design: Multiple nested case study using concurrent mixed methods approaches. *: Health care providers: clinicians, health managers, policy makers involved in provision and delivery of care and services to persons living with cancer; C: Context; M: Mechanisms; O: Outcomes; QUAL: qualitative data; QUAN: quantitative data. References: a: Miles MB, Huberman M, Saldana J. Qualitative data analysis. A methods sourcebook. 3rd ed. Thousand Oaks, CA: SAGE Publications; 2014. b: Creswell J. Research design: qualitative, quantitative, and mixed methods approaches. 4 ed. Thousand Oaks, CA: SAGE Publications; 2013 
Table 1 Characteristics of the cancer networks participating in the study

\begin{tabular}{|c|c|c|c|c|}
\hline Cancer network (microcase) & 1 & 2 & 3 & 4 \\
\hline Geographic location & Rural/Semi-urban area & Metropolitan area & Metropolitan area & Rural/Semi-urban/Urban area \\
\hline Surface $\left(\mathrm{km}^{2}\right)$ & $>10,000$ & $<100$ & $<100$ & $>1000$ \\
\hline Population $(M)$ & $>400,000$ & $<400,000$ & $>400,000$ & $<400,000$ \\
\hline \multicolumn{5}{|l|}{ Cancer services offered } \\
\hline Radiotherapy & As per inter-regional service agreement & In the region & In the region & At the Integrated Cancer Centre \\
\hline Integrated Cancer Centre & Launched & No & No & Yes \\
\hline \multicolumn{5}{|l|}{ Networked healthcare settings } \\
\hline Hospitals (N) & 5 & 2 & 3 & 2 \\
\hline Community health centres ${ }^{\mathrm{a}}(\mathrm{N})$ & 26 & 8 & 6 & 7 \\
\hline Family medicine groups ${ }^{\mathrm{b}}(\mathrm{N})$ & 39 & 7 & 12 & 10 \\
\hline Network development stage & Emergent & Emergent & Intermediary & Mature \\
\hline
\end{tabular}

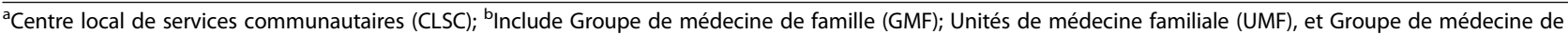
famille universitaire (GMF-U)

\section{Participants}

The inclusion criteria under study for caregivers are: being a health professional, manager, policy maker, or a PLC representative involved in governance and, directly or indirectly, in the provision of care to PLCs. All participants will sign a consent form approved by a recognized research ethics board. Throughout the study, ethical considerations will be addressed through a relational and collaborative approach, particularly with study participants, including the PLCs [80, 81].

The inclusion criteria for PLCs are: having a confirmed diagnosis of a type of cancer (lung, breast, colorectal, prostate) selected based on the number of new cases and the toxicity of the treatment that may have an impact on health-related quality of life [82], reading and understanding French, having a care experience of at least two cancer treatments or early palliative (non-end of life) treatments, and having the physical and cognitive capacity to answer a questionnaire of about $20 \mathrm{~min}$. This capacity will be determined in collaboration with clinicians who know the potential participants.

\section{Qualitative data collection}

The collection of qualitative data from various sources and methods [75] will focus on contextual factors and mechanisms surrounding CG in the QCN as perceived by stakeholders (Objectives 1,2). The triangulation of sources and methods should compensate for their respective inherent limitations [83] and contribute to the study's internal validity [84].

\section{Field documents}

The document review will be conducted to form an initial idea of what is happening in the cancer networks with respect to $\mathrm{CG}$. Documents collected will include meeting minutes, action plans, regional and government reports, and scientific literature.

\section{Focus groups}

Heterogeneous focus groups of six to eight participants per case [85], selected on the basis of intentional sampling based on their role in the QCN and their knowledge of governance issues, will be formed. Care providers in the roles of medical and clinical-administrative co-manager, cancer services representative, performance evaluation manager, or PLC representatives will be invited to participate. The facilitation $(n=4)$ will be led by an experienced person with excellent knowledge of cancer care and services.

\section{Interviews}

After a first cycle of document analysis, semi-structured individual interviews will be conducted with key informants and representatives of government departments involved in cancer research (public health, primary care, medical care, and nursing). Based on our previous studies and the literature [86, 87], approximately 15 participants per case and about 10 at the provincial level (total $n=70$ ) will be required. This number will be adjusted according to the nature and redundancy of the data [87].

\section{Data collection grids}

Emerson's framework [64], itself based on the founding work of Ansell and Gash [88], has been adapted to guide the collection of qualitative data on CG mechanisms and their outcomes (Fig. 2 and Additional file 1). Emerson et al. explicitly defined the components of their model $[64,89]$. Data collection grids, developed from the concepts of this analytical framework, will be used and their content adapted according to the nature of the 


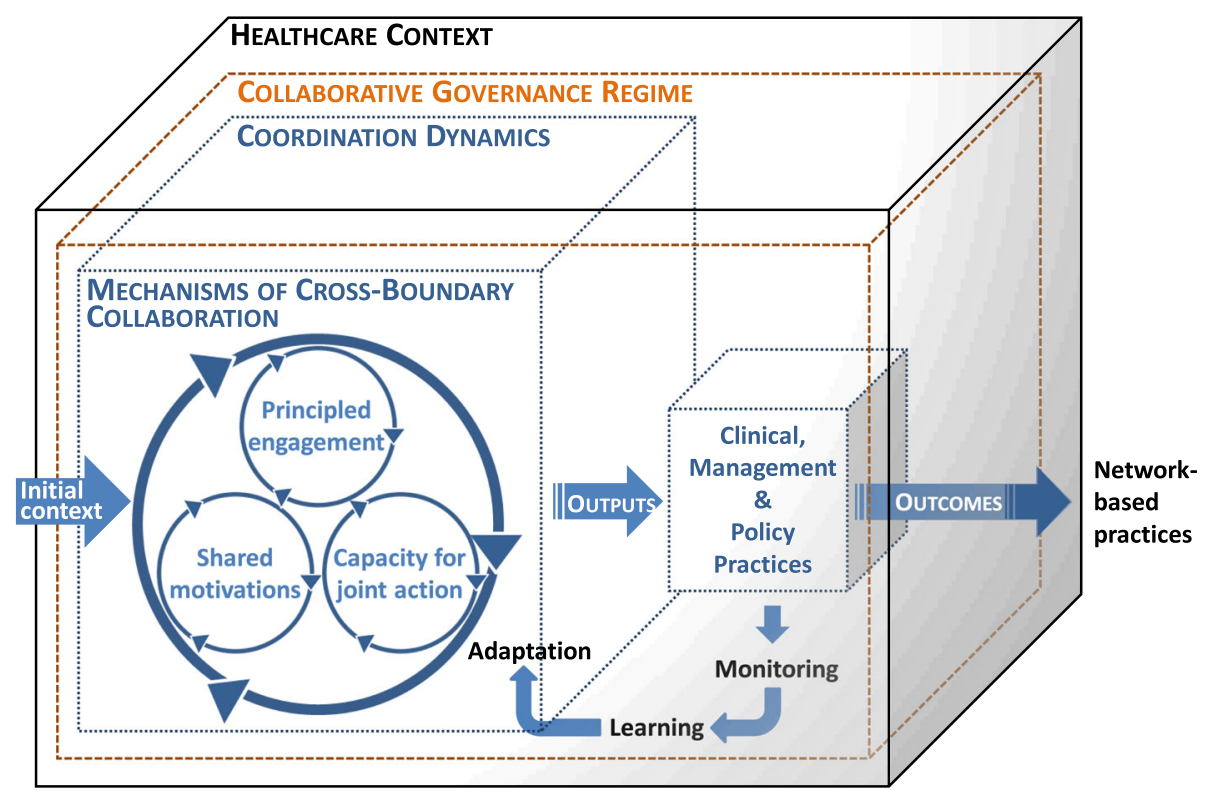

Fig. 2 Cancer network collective governance framework. The framework has been adapted from Emerson [64, 89] and integrated with Pawson and Tilley's concepts [73]

information sought and the type of actors. The data sought will focus on the characteristics of the context (history, opportunities, constraints), the characteristics of the actors (values, leadership, management strategies, resources), the dynamics of collaboration (instruments, strategies, evolution over time), the perceived influence of these dynamics on the care experience, the healthrelated quality of life of PLCs, and the costs related to the use of services. Participants will also be asked to describe facts or incidents, expected or not, that have more critically influenced CG and the resulting collaborative dynamics.

\section{Qualitative analysis}

The audio data recorded during the interviews and focus groups will be transcribed and stored in a formal database managed using QDA Miner Software version 4.1.21 [90]. Analysis of qualitative data will begin as soon as the first data become available and will follow cyclical thematic analysis techniques based on our analytical framework: structural coding followed by interpretive analysis [91]. The intra-case analysis will be followed by an inter-case analysis to contrast the differences and similarities in the recursive mechanisms of CG from a vertical perspective (between levels of governance) and horizontal perspective (between and within teams). Associations between critical contextual factors and collaborative governance mechanisms will be constructed according to the principles of realist evaluation [73] and our research objectives. The validity of the QUAL results will be ensured by the use of an analytical framework with theoretical foundations (Additional file 1), multiple triangulation [92] of data sources, methods and researchers with varied expertise, and the involvement of collaborators and PLCs to ensure the plausibility of findings. QUAL+QUAN data will be integrated using a convergent approach to highlight differences and allow some combination of QUAL+QUAN results [78]. Transferability will be maximized by developing a rich description of contexts and mechanisms [91].

\section{Quantitative data collection}

The quantitative data collected will allow the quantification of GC outcomes on care providers and PLCs as well as the financial burden of cancer in terms of expenditures incurred by PLCs and the cost to the healthcare system of the services used. The data collection will be based on a concurrent mixed methods approach to complement the qualitative data (Objectives 1,2 ) and measure the outcomes associated with CG (Objective 3) [78].

\section{Health care provider questionnaires}

The description of the questionnaires that will be used for the collection is presented in Additional file 2. Relational coordination [93], Practice Environment Checklist (PEC) [94] and teamwork [95] are operational proxies at the clinical and organizational level for the desired CG outcomes for care providers. The sample size of the caregivers should be 30 for each case (total $n=4 * 30=120$ ) considering a minimum response rate of $35 \%$. The inclusion criteria are: being a professional or manager involved in governance 
and directly or indirectly involved in providing care to PLCs.

The questionnaire will be self-administered electronically on SurveyMonkey to individuals directly or indirectly involved in the provision of care to PLCs in each case as well as to individuals involved at the political level (MSSS and provincial coordinating committee).

\section{Questionnaires for persons living with and beyond cancer}

Outcome measurement for PLCs includes care experience, health-related quality of life, clinical information and expenses incurred as perceived by PLCs (patient-reported experience measure) [96] (Additional file 2). The care experience will be operationalized by the Health System Responsiveness questionnaire [97], health-related quality of life by the EuroQoL EQ-5D-5 L questionnaire and analogous visual scale [98], clinical information by the self-administered comorbidity questionnaire [99], and out-of-pocket expenditures by the Patient SelfAdministered Financial Expenditure questionnaire [100]. These measurements will be taken 1 week after a surgery or after the second anti-cancer treatment (T0) at six and 12 months (T1 and T2), following International Consortium for Health Outcomes Measurement (ICHOM) guidelines [25, 101-103]. Although the ICHOM recommendations suggest a baseline at diagnosis at the physician's office, our choice of T0 is intended to capture outcomes associated with "exposure" to relational coordination (RC) and to avoid adding to the potential distress of some PLCs by asking them to participate in a study right when they are receiving their diagnosis. Sociodemographic, clinical, and organizational data characterizing the sample that are potentially confounding variables will be collected according to ICHOM recommendations: sex, age, income, education, marital status, postal code, and self-reported comorbidities. As for the size of the PLC sample, a total of 356 respondents will have to be recruited to detect an average difference of 0.08 with a standard deviation of 0.4 and a correlation of 0.1 for health-related quality of life between measurement times [104]. A response rate of $70 \%$ is being assumed, based on our previous studies [12, 47].

\section{Clinical records}

Clinical results will be obtained from patient medical records, including the Outil de dépistage de la détresse (screening for distress tool - ODD) used in current practice in Quebec [105]. The ODD includes three scales: 1) the Distress Thermometer (DT) [106], a visual distress scale rated from 0 to 10 (10 being the highest level); 2) the revised Edmonton Symptom Assessment Scale (ESAS-R) to assess nine common cancer symptoms (pain, fatigue, drowsiness, nausea, anorexia, dyspnea, depression, anxiety, well-being) on a scale of 0 to 10 (10 being the worst manifestation of the symptom) [107, 108]; and 3) the Canadian Problem Checklist consisting of 24 items in the version promoted in Quebec [105]. The ODD data, including whether or not there is an active intervention, will be collected through a review of the patient record. There are different ways to clinically interpret these items, but we have selected the following scale: mild $<3$, moderate $=4-6$ and severe $\geq 7$ [105].

\section{Administrative data}

The costs associated with the use of services will be calculated over a one-year period as with QALY measurements. They are in two areas: costs to the healthcare system and those incurred by PLCs [109]. Costs to the healthcare system include: hospitalizations, treatments and outpatient oncology and emergency room visits, drugs reimbursed by the Régie d'assurance-maladie du Québec (RAMQ) (Quebec's health insurance plan agency), and physician fees. These costs will be calculated based on data from RAMQ's medical and pharmaceutical services databases and the Quebec ministry of health and social services (MSSS) (MED-ECHO database). Unit costs for each type of service will be calculated from the MSSS's annual budget and activity reports (AS-471, AS-478) submitted by each healthcare facility in Quebec. The average cost for care to PLCs (medical and general costs) can therefore be determined from the financial statements of each case in the study based on public reports. Physician fees, which include all medical procedures invoiced by physicians to the RAMQ that are not included in these reports, will be captured from the RAMQ along with the relative intensity levels of resources used. These data will provide an individual cost estimate for hospitalizations. Unit costs of medical services will be calculated for the most recent full fiscal year using a methodology published by two of the co-investigators [110]. Costs for outpatient oncology clinic visits and emergency room visits will be assessed on a cost-per-visit basis. Costs for hospitalizations include costs for hospital stay (cost per day) and day surgeries (cost per surgery). The RAMQ's pharmaceutical services database will be used as a source for the costs of covered drugs.

\section{Quantitative analyses}

The validity of quantitative results is based on the use of questionnaires with demonstrated psychometric qualities and implementation of the analysis plan under the guidance of co-investigators with solid expertise. Statistical analyses will be performed using IBM SPSS Statistics version 25 [111] and SAS 9.4 [112]. Values of $p<0.05$ will be considered significant. Missing data for the variables will be imputed using the multiple imputation technique. Descriptive statistics will be used to summarize sociodemographic and clinical variables for PLCs and professional experience variables for care providers at each site. 
Student tests or non-parametric tests such as the MannWhitney test and ANOVA tests will be used for continuous variables. For categorical variables, square Chi-square tests will be used to identify differences between groups. Univariate and multivariable linear and logistic regression analyses will be conducted to explore the relationship between CG (mini-PEC and RC) and PLC characteristics, provider characteristics, and other site characteristics. We will use the strategy of Labbé et al. to identify the breaking points of clinically significant characteristics [104]. For the care experience, we will use the breakpoints between a positive vs. less positive experience used in our previous work [12]. Subsequently, multiple regression analyses will be conducted to determine the association between the independent variable $(\mathrm{RC}+$ mini-PEC) and the dependent variables (four reactivity subscales, three ODD dimensions, EQ-5D-5 L-EVA) by controlling for potentially confounding variables (PLC and site characteristics). The Incremental Cost-Effectiveness Ratio (ICER $=\Delta$ Cost $/ \Delta E$ Efectiveness) will be estimated using a multivariate bootstrap, and cost-effectiveness acceptability curves will be constructed.

\section{Integrated knowledge translation}

Our approach to intervention research in partnership with field actors, combined with the principles of realist evaluation, is based on a process of two-way exchange of knowledge and expertise between producers and users of research results involved in defining problems and constructing solutions [81, 113, 114]. This approach is strategically chosen because of its potential to accelerate the visibility of gains $[81,113]$, the positive influence it is recognized to have on the adoption of new practices based on research evidence, as well as its potential contribution to the management of complex problems $[115,116]$.

In order to translate the intermediate and final results of the study into impacts in the community, a knowledge transfer plan has been developed. The specific activities of our study are shown in Table 2. The components of the Knowledge to Action framework are the cornerstone for updating our IKT plan [81]. IKT is a dynamic and recursive process that encompasses the synthesis, dissemination, exchange and application of knowledge to improve the delivery of care

Table $\mathbf{2}$ Integrated knowledge translation activities

\begin{tabular}{|c|c|}
\hline Target & Knowledge translation activities integrated into research \\
\hline $\begin{array}{l}\text { On-site collaborators, including persons living with and beyond } \\
\text { cancer, clinicians, healthcare managers, and policy makers }\end{array}$ & $\begin{array}{l}\text { - Announcement of the funding of the study during the Quebec Cancer } \\
\text { Program Symposium } \\
\text { - Strategic meetings with knowledge users (e.g. opinion leaders, collaborators) } \\
\text { using bidirectional exchanges, deliberative process and reflexive approach } \\
\text { throughout the research process to ensure early detection of obstacles, } \\
\text { facilitating elements, controversies, and solutions } \\
\text { - Access to the research team for on-site collaborators } \\
\text { - Diffusion of newsletters or brief reports every } 4 \text { months reporting study } \\
\text { progress and learnings } \\
\text { - Discussions around the intermediate findings of the study in site meetings }\end{array}$ \\
\hline Academic communities & $\begin{array}{l}\text { - Involvement of junior researchers in teaching cancer care delivery: graduate } \\
\text { students, physicians and health professionals } \\
\text { - Diffusion of study results in classes lectured by the study researchers and } \\
\text { collaborators in six different universities } \\
\text { - Contribution to training and continuing education of health professionals } \\
\text { - Mobilization of research networks in Quebec and Canada }\end{array}$ \\
\hline Large scale & $\begin{array}{l}\text { - Mobilization of partner networks: Direction générale de cancérologie (National } \\
\text { Cancer Directorate), cancer networks, Institut national d'excellence en santé et en } \\
\text { services sociaux (National Institute for Excellence in Health and Social Services) } \\
\text { - Access to university and interuniversity networks: Quebec Network on Nursing } \\
\text { Intervention Research (RRISIQ), Chaire de recherche sur la qualité et la sécurité } \\
\text { des soins aux personnes atteintes de cancer de I'Université de Sherbrooke, } \\
\text { Chaire Santé et Territoire du Groupe de recherche Asclépios de I'Université } \\
\text { Clermont-Auvergne } \\
\text { - Presentations in conferences: Multinational Association of Supportive Care in } \\
\text { Cancer (MASCC), Canada's Applied Research in Cancer Control Conference, } \\
\text { Union for International Cancer Control (UICC), ASCO Palliative and Supportive } \\
\text { Care in Oncology Symposium } \\
\text { - Publication of the results on the website of Prof. Tremblay's Research Chair to } \\
\text { allow continuing knowledge transfer about the issues pertaining to } \\
\text { collaborative governance } \\
\text { - Publications in open access journals }\end{array}$ \\
\hline Dissemination & $\begin{array}{l}\text { - Creation and use of communication tools to disseminate the results of the } \\
\text { study, adapted to target audiences, including summary documents (research } \\
\text { notes or policy briefs) for policy makers, clinicians, and the general public. }\end{array}$ \\
\hline
\end{tabular}


and strengthen the healthcare system [117]. This process will be part of a complex network of producer-user interactions, whose intensity, complexity, and degree of engagement can be adapted according to the results we obtain and the particular needs of each user.

Our interdisciplinary team (medicine, nursing, organi zation/management of services, sociology, management sciences, epidemiology, economics) is composed of leaders with the ability to reach governing actors of the QCN in Quebec. Knowledge mobilization has already begun with the composition of our team during the discussions to continue to work together on developing the QCN and making it sustainable. Knowledge mobilization is approached as a "contact sport" whose strategies are organized "around the water cooler" [118]. This metaphor illustrates the importance of creating relational spaces (virtual or face-toface) between producers and users of research through a deliberative exchange process [119]. A reflexive approach and the presence of opinion leaders during these exchanges make it possible to clearly identify the representations that stakeholders have of the mechanisms of CG and its outcomes, and to identify realistic actions.

\section{Discussion}

The sometimes contradictory findings on networks' outcomes can be explained in part by the conceptual and methodological challenges of establishing causal links between integrated network operation and its outcomes on the quality of services or even population health [40]. Empirical studies, including ours, show variations in network implementation and degree of integration with mixed and sometimes unanticipated outcomes without having captured the sequence of mechanisms that explain these results $[10,40,72]$. One of the reasons is the lack of data on governance in these networks. In addition, most network studies are conducted over the short term, although it is recognized that interventions at the interface between clinic and organization take time [10].

Focusing on a CG model and its outcomes on the provision of care, our study responds to the challenge of innovating to address the issues of quality of care for PLCs, namely the increasing number of people receiving a new cancer diagnosis, the increasing number of those who survive it, and maintaining access to quality care in a context of scarce human resources and rising treatment costs [1]. It takes into account the difficulty of achieving the outcomes envisioned in cancer policies and programs [120].

Because of its pragmatic approach with close interaction between producers and users of research results, our study offers a strong potential for impact by making the QCN a learning organization [3]. The potential impact of our study on the network's capacity for transformation will be observed at all three levels of the QCN's care delivery: political, organizational, and clinical.
At the political level, the QCN's capacity to transform the supply of care refers to the way in which government actors organize themselves to ensure that the national cancer control plan is implemented in a way that solves the problems of the supply of care and services to PLCs. However, this capacity depends on a wide variety of expertise from biology to sociology and from economics to epidemiology [121], expertise contributed by the members of our team that will have an impact on the ability to ensure the development of the QCN.

At the organizational level, managers have an important role to play in translating the elements of the national cancer plan into the specificities of their environment. Our study of CG will have an impact on four important aspects of their work in institutionalizing the network practices [122] promoted in the national cancer plan: 1) structural work: efforts to formalize roles, operating modes, resource allocation; 2) conceptual work: values, norms, and systems of representation; 3) operational work: concrete actions to guide clinicians' behaviours and clinical practices; and 4) relational work: development of relationships, trust and collaboration among professionals involved in the provision of PLC care (encompassing the other three aspects) [48]. Our study on CG will provide access to data that can guide how managers carry out these aspects of their work.

At the clinical level, our study is the first to provide data on CG mechanisms where clinicians and PLCs are involved with government stakeholders to implement the national cancer plan. The study will impact the development of these new roles with the potential to reduce the gap between what is prescribed at the policy level (macro) and the delivery of care and services (micro) for which there is very little cancer-specific research data. Ultimately, our study will have an impact on organizations' practices regarding the ratio of results to costs.

\section{Study challenges and mitigation strategies}

There are some operational challenges in conducting the study. Different means have been devised to overcome these challenges.

The efforts required to maintain cohesion of the interdisciplinary research team, which includes several researchers and collaborators in different universities and research centres, should not be underestimated in this study involving a diversity of expertise. A steering committee (coordination and monitoring) and an advisory committee (interpretation of intermediate results) will be set up and a systematic evaluation of the conduct of meetings [123] and the satisfaction of participating in a community of practice [124] will make it possible to act to maintain interest. In addition, the study will be coordinated by a research professional. 
The engagement and mobilization of health care providers in research, which is critical to achieving the objectives, is a challenge in a healthcare system undergoing transformation. Measures will be implemented to retain participation of care providers in the study, including information sessions on the benefits of the study, management support to facilitate participation, links established during the initial study, and monetary compensation for participation.

As for PLCs, the main challenge to their participation is likely to be the time and effort (availability, duration) required to participate in the data collection stages. They will be able to choose the time and place for the individual interviews. Particular care has been taken to select short and easy-to-use questionnaires for PLCs. In addition, the importance that sharing their experience represents as a contribution to the study will be highlighted, and monetary compensation will be offered in recognition of this contribution.

The large amount and diversity of data [125] could also pose challenges in terms of information storage and management. The QDA Miner, SPSS, and SAS software will facilitate the management, analysis and integration of qualitative, quantitative, and mixed data.

\section{Conclusion}

With significant effort and resources being devoted to cancer networks, it is imperative to produce robust and rapidly usable research results to support decision-making on its future. The study of CG in cancer networks will contribute to an integrated understanding of vertical coordination between the levels of governance: between what is prescribed at the political level and what is actually happening in care and service teams, as well as horizontal coordination (between and within teams). This is a major challenge for the constant evolution of cancer networks and to ensure the sustainability of their benefits. Finally, it is important to determine whether the dynamics of collective governance of the network provide added value, i.e. better care outcomes for every dollar invested.

\section{Supplementary information}

Supplementary information accompanies this paper at https://doi.org/10. 1186/s12913-019-4586-z.

Additional file 1: Cancer network collaborative governance framework. Figure S1. Cancer network collaborative governance framework. Table S1. Concepts and definitions pertaining to Emerson's collaborative governance framework and their contextualization to cancer networks. Table S2. Dimensions, components, and definitions of Emerson's collaborative governance framework and their contextualization to cancer networks.

Additional file 2: Operationalization of variables. Table S1. List and description of quantitative data collection questionnaires.

\section{Abbreviations}

C: Context: CG: Collaborative governance; M: Mechanism; O: Outcome:

PLC: Person living with and beyond cancer; QALY: Quality-adjusted life years;
QCN: Quebec Cancer Network; QUAL: Qualitative; QUAN: Quantitative; RC: Relational coordination

\section{Acknowledgements}

We are grateful to our collaborators in the participating health care establishments for their commitment and support.

\section{Authors' contributions}

DT and NT contributed equally to the study background and design and wrote the draft manuscript. $\mathrm{KB}$ and $\mathrm{JH}$ contributed to the description of the professional component of the intervention; HMV and TP contributed to the design of cost analyses associated with health service utilization; DB contributed to statistical methods; J-LD contributed to strategical aspects of research by providing expertise on healthcare system policy and governance; MPP reviewed drafts of the manuscript to ensure the study is relevant from a patient-partnership perspective in the context of cancer services, and $\mathrm{JH}$ and $C P$ reviewed drafts of the manuscript to integrate a knowledge user perspective and ensure the feasibility of the intervention components. GR drafted the knowledge translation plan. LL contributed as the research coordinator and organized the additional material files. All authors read and approved the final manuscript.

\section{Funding}

This study is supported by a grant (number 265874) from the Oncopole which is financed by Fonds de recherche du Québec - Santé (FRQS, Quebec's Research Funds - Healt), a major funding agency in Quebec, Canada, and the Cancer Research Society (CRS). The study protocol was peer-reviewed under the ONCOPOLE EMC2 competition. This funding agency and its partners have not had any role in preparing, reviewing, or approving the manuscripts.

\section{Availability of data and materials}

The datasets generated and/or analyzed during the current study will be available from the corresponding author on reasonable request. All data generated or analyzed during this study will be included in upcoming published articles.

\section{Ethics approval and consent to participate}

Approval from the Research Ethics Board of the Research Centre of Centre intégré de santé et de services sociaux de la Montérégie-Centre was obtained for all study procedures in participating health service centres (file number: MP-04-2019-316). Informed consent will be obtained from all participants. Confidentiality will be respected and data security ensured according to the rules governing health services centres and set by the Research Ethics Board of the Research Centre of Centre intégré de santé et de services sociaux de la Montérégie-Centre. All participating sites formally involved in the study committed to participate in the study. Recruitment and data collection for this study has begun in May 2019 and will continue for the next two years.

\section{Competing interests}

JLD is a member of the editorial board (Associate Editor) of this journal. The other authors have no competing interests to declare.

\section{Author details}

${ }^{1}$ Faculté de médecine et des sciences de la santé, Campus de Longueuil Université de Sherbrooke, 150 Place Charles-Le Moyne, Longueuil, Québec J4K 0A8, Canada. ${ }^{2}$ Centre de recherche Charles-Le Moyne - SaguenayLac-Saint-Jean sur les innovations en santé (CR-CSIS), Centre intégré de santé et de services sociaux de la Montérégie-Centre, 150 Place Charles-Le Moyne, Longueuil, Québec J4K 0A8, Canada. 'École Nationale d'Administration Publique, 4750 Henri-Julien Avenue, Montréal, Québec H2T 3E5, Canada. ${ }^{4}$ Département de gestion, d'évaluation et de politique de santé, École de santé publique, Université de Montréal, 7101, avenue du Parc, 3e étage, Montréal, Québec H3N 1X9, Canada. ${ }^{5}$ Centre de recherche de I'Institut Universitaire en Santé Mentale de Montréal, 7331, rue Hochelaga, Montréal, Québec H1N 3V2, Canada. 'École de gestion, Université de Sherbrooke, 2500, boulevard de I'Université, Sherbrooke, Québec J1K 2R1, Canada. ${ }^{7}$ Centre de recherche du Centre Hospitalier de I'Université de Sherbrooke (CR-CHUS), 3001, 12e Avenue Nord, Sherbrooke, Québec J1H 5N4, Canada. ${ }^{8}$ Faculté des sciences infirmières, Université de Montréal, 2375 chemin Côte-Ste-Catherine, Montréal, Québec H3T 1A8, Canada. ${ }^{9}$ Centre de recherche du Centre 
hospitalier de I'Université de Montréal (CR-CHUM), 850, rue Saint-Denis, Montréal, Québec H2X 0A9, Canada. ${ }^{10}$ École de santé publique, Université de Montréal, 7101, avenue du Parc, Montréal, Québec H3N 1X9, Canada. ${ }^{11}$ Centre de recherche en droit public, Université de Montréal, 3101, chemin de la Tour, Montréal, Québec H3T 1J7, Canada. ${ }^{12}$ Institut de recherche en santé publique de l'Université de Montréal (IRSPUM), Université de Montréal, 7101, avenue du Parc, Montréal, Montréal, Québec H3N 1X9, Canada. ${ }^{13}$ Département des sciences infirmières, Campus de Lévis - Université du Québec à Rimouski (UQAR, 1595, boulevard Alphonse-Desjardins, Lévis, Québec G6V 0A6, Canada. ${ }^{14}$ Hôtel-Dieu de Lévis, Centre de recherche du CISSS de Chaudière-Appalaches, 143, rue Wolfe, Lévis, Québec G6V 3Z1, Canada. ${ }^{15}$ Centre de recherche du Centre hospitalier universitaire de Québec (CRCHUQ), 11 Côte du Palais, Québec, Québec G1R 2J6, Canada. ${ }^{16}$ Équipe de recherche Michel-Sarrazin en oncologie psychosociale et soins palliatifs (ERMOS), Maison Michel-Sarrazin, 9, rue McMahon, Québec, Québec G1R 3S3, Canada. ${ }^{17}$ Faculté des sciences infirmières, Université Laval, 1050, avenue de la Médecine, Pavillon Ferdinand-Vandry, Québec, Québec GIV 0A6, Canada. ${ }^{18}$ Axe Santé des populations et pratiques optimales en santé, Centre de recherche du CHU de Québec-Université Laval, 10, rue de l'Espinay, Québec, Québec G1L 3L5, Canada. ${ }^{19}$ Centre de recherche sur les soins et les services de première ligne de l'Université Laval (CERSSPL-UL), 2525, chemin de la Canardière, Québec, Québec G1J OA4, Canada. ${ }^{20}$ Centre intégré de santé et de services sociaux de la Montérégie-Centre, 3120 boulevard Taschereau, Greenfield Park, Québec J4V 2H1, Canada. ${ }^{21}$ Centre intégré de cancérologie de la Montérégie, 3120 Boulevard Taschereau, Greenfield Park, Québec J4V 2G9, Canada.

\section{Received: 21 August 2019 Accepted: 9 October 2019} Published online: 25 October 2019

\section{References}

1. American Society of Clinical Oncology. The state of cancer care in America, 2017: a report by the American Society of Clinical Oncology. J Oncol Pract. 2017;13(4):e353-e94.

2. Ministère de la Santé et des Services sociaux (MSSS). La lutte contre le cancer dans les régions. Un premier bilan. Québec: Programme québécois de lutte contre le cancer, Ministère de la Santé et des Services sociaux; 2003. http://publications.msss.gouv.qc.ca/msss/document-001377/. Accessed 16 May 2019

3. Abernethy AP, Etheredge LM, Ganz PA, Wallace P, German RR, Neti C, et al. Rapid-learning system for cancer care. J Clin Oncol. 2010;28(27):4268-74.

4. Turrini A, Cristofoli D, Frosini F, Nasi G. Networking literature about determinants of network effectiveness. Public Adm. 2010;88(2):528-50.

5. Taplin SH, Anhang Price R, Edwards HM, Foster MK, Breslau ES, Chollette V, et al. Introduction: understanding and influencing multilevel factors across the cancer care continuum. J Natl Cancer Inst Monogr. 2012;2012(44):2-10.

6. Liberati EG, Gorli M, Scaratti G. Invisible walls within multidisciplinary teams: disciplinary boundaries and their effects on integrated care. Soc Sci Med. 2016;150:31-9.

7. Ferlie E, Fitzgerald L, McGivern G, Dopson S, Bennett C. Managed Cancer Networks: exemplars of evidence-based governementality. In: Making Wicked Problems Governable? The case of managed networks in health care. Oxford: Oxford Universty Press; 2013. p. 73-96.

8. Yatim F, Minvielle E. Quel mode d'action publique pour améliorer la coordination des soins? Politiques et Management Public. 2016;33(1):27-48.

9. Commissaire à la santé et au bien-être. La performance du système de santé et de services sociaux québécois 2016: Gouvernement du Québec; 2017. http://www.csbe.gouv.qc.ca/fileadmin/www/2017/ PerformanceGlobale/CSBE_RapportGlobal_2016_ACCESS.pdf. Accessed 16 May 2019

10. Roberge D, Denis J-L, Cazale L, Comtois É, Pineault R, Touati N, et al. Évaluation du réseau intégré de soins et de services en oncologie: l'expérience de la Montérégie. Ottawa: Fondation canadienne de la recherche sur les services de santé; 2004. http://www.cfhi-fcass.ca/migrated/ pdf/researchreports/ogc/roberge_2_final.pdf Accessed 16 May 2019

11. Touati N, Roberge D, Denis J-L, Pineault R, Cazale L, Tremblay D. Governance, health policy implementation and the added value of regionalization. Healthc Policy. 2007;2(3):97-114.

12. Tremblay D, Roberge D, Touati N, Maunsell E, Berbiche D. Effects of interdisciplinary teamwork on patient-reported experience of cancer care. BMC Health Serv Res. 2017;17(1):218 Tremblay2017.
13. Taplin SH, Weaver S, Chollette V, Marks LB, Jacobs A, Schiff G, et al. Teams and teamwork during a cancer diagnosis: interdependency within and between teams. J Oncol Pract. 2015;11(3):231-8.

14. D'Amour D, Tremblay D, Proulx M. Déploiement de nouveaux rôles infirmiers au Québec et pouvoir médical. Recherches sociographiques; 2009. p. 301-20.

15. Tremblay D, Latreille J, Bilodeau K, Samson A, Roy L, L'Italien M-F, et al. Improving the transition from oncology to primary care teams: a case for shared leadership. J Oncol Pract. 2016;12(11):1012-9.

16. Union for International Cancer Control. World Cancer Declaration 2013. New York: Union for International Cancer Control; 2013. http://www.uicc.org/ sites/main/files/private/131119_UICC_WorldCancerDeclaration_2013_1.pdf. Accessed 16 May 2019

17. World Health Organization (WHO). National cancer control programmes: policies and managerial guidelines. Geneva: World Health Organization; 2002. https://apps.who.int/iris/bitstream/handle/10665/42494/9241545577. pdf? sequence=1\&isAllowed=y. Accessed 16 May 2019

18. Institut National du Cancer (INCa). Guérir et prévenir les cancers : donnons les mêmes chances à tous et partout en France. In: Plan cancer 2014-2019. Boulogne Billancourt: Ministère des Affaires sociales et de la Santé; 2014 http://www.bdsp.ehesp.fr/Base/480572/. Accessed 16 May 2019.

19. McConigley R, Platt V, Holloway K, Smith J. Developing a sustainable model of rural cancer care: the Western Australian Cancer network project. Aust Rural Health. 2011;19(6):324-8.

20. Kewell B, Hawkins C, Ferlie E. Calman-Hine reassessed: a survey of cancer network development in England, 1999-2000. J Eval Clin Pract. 2002;8(3):303-11.

21. Ministère de la santé et des services sociaux. Le bilan des réalisations des orientations prioritaires 2007-2012 du Programme québécois de lutte contre le cancer, incluant l'état de la situation 2011-2012. http:// publications.msss.gouv.qc.ca/acrobat/f/documentation/2011/11-902-16.pdf. Accessed 16 May 2019.

22. Ministère de la Santé et des Services sociaux. Programme québécois de lutte contre le cancer. In: Pour lutter efficacement contre le cancer, formons équipe. Québec: Comité consultatif sur le cancer; 1997. http://publications. msss.gouv.qc.ca/acrobat/f/documentation/1997/97-729-5.pdf. Accessed 16 May 2019.

23. Provan KG, Kenis P. Modes of network governance: structure, management, and effectiveness. J Public Adm Res Theory. 2008;18(2):229-52.

24. Haines M, Brown B, Craig J, D'Este C, Elliott E, Klineberg E, et al. Determinants of successful clinical networks: the conceptual framework and study protocol. Implement Sci. 2012;7:16.

25. Provan KG, Beagles JE, Leischow SJ. Network formation, governance, and evolution in public health: the north American Quitline consortium case. Health Care Manag Rev. 2011;36(4):315-26.

26. Provan KG, Milward HB. A preliminary theory of interorganizational network effectiveness: a comparative study of four community mental health systems. Adm Sci Q. 1995;40(1):1-33.

27. Kaluzny AD, Warnecke RB. Managing a health care alliance: improving community cancer care. 2nd ed. Washington, DC: Beard Books; 2000.

28. Foglino S, Bravi F, Carretta E, Fantini MP, Dobrow MJ, Brown AD. The relationship between integrated care and cancer patient experience: a scoping review of the evidence. Health Policy. 2016;120(1):55-63.

29. Bernabei R, Landi F, Zuccala G. Health care for older persons in Italy. Aging Clin Exp Res. 2002;14(4):247-51.

30. Kodner D. Whole-system approaches to health and social care partnerships for the frail elderly: an exploration of north American models and lessons. Health Soc Care Community. 2006;14(5):384-90.

31. MacAdam M. Frameworks of integrated care for the elderly: a systematic review: Canadian Policy Research Networks; 2008. http://brainxchange.ca/ Public/Files/Primary-Care/HQPC/Care-of-the-Eldery-integrate-care.aspx. Accessed 16 May 2019

32. Wedding U, Kodding D, Pientka L, Steinmetz HT, Schmitz S. Physicians' judgement and comprehensive geriatric assessment (CGA) select different patients as fit for chemotherapy. Crit Rev Oncol Hematol. 2007;64(1):1-9.

33. Hebert R, Raiche M, Dubois MF, Gueye NR, Dubuc N, Tousignant M. Impact of PRISMA, a coordination-type integrated service delivery system for frail older people in Quebec (Canada): a quasi-experimental study. J Gerontol B Psychol Sci Soc Sci. 2010;65b(1):107-18.

34. Béland F, Bergman $H$, Lebel $P$, Dallaire L, Fletcher J, Tousignant $P$, et al. Integrated services for frail elders (SIPA): a trial of a model for Canada. Can J Aging. 2006;25(1):5-42. 
35. Leung A, Yau D, Liu C, Yeoh C, Chui T, Chi l, et al. Reducing utilisation of hospital services by case management: a randomised controlled trial. Aust Health Rev. 2004;28(1):79-86.

36. Black D. Case management for elderly people in the community: the Evercare model improves quality of care but does not reduce emergency admissions or mortality. BMJ. 2007;334(7583):3-4.

37. Long M, Marshall B. What price an additional day of life? A costeffectiveness study of case management. Am J Manag Care. 2000;6(8): 881-6.

38. Adler PS, Kwon S-W, Heckscher C. Professional work: the emergence of collaborative community. Organ Sci. 2008;19(2):359-76.

39. Ferlie EB, Fitzgerald L, Wood M, Hawkins C. The nonspread of innovations: the mediating role of professionals. Acad Manag J. 2005;48(1):117-34.

40. Ferlie E, Fitzgerald L, McGivern G, Dopson S, Exworthy M. Networks in health care: a comparative study of their management, impact and performance. In: Report for the National Institute for Health Research Service Delivery and Organisation Programme. London: Queen's Printer and Controller of HMSO 2010; 2010. http://www.netscc.ac.uk/hsdr/files/project/ SDO_FR_08-1518-102_V01.pdf. Accessed 16 May 2019.

41. Molin MD, Masella C. From fragmentation to comprehensiveness in network governance. Public Organ Rev. 2016;16(4):493-508.

42. MacLeod H. Local health integration networks: build on their purpose. Healthc Manage Forum. 2015;28(6):242-6.

43. Noseworthy T, Wasylak T, O'Neill B. Strategic clinical networks in Alberta: structures, processes, and early outcomes. Healthc Manage Forum. 2015; 28(6):262-4.

44. Six P, Goodwin N, Peck E, Freeman T. Managing networks of twenty-first century organisations. Basingstoke: Palgrave Macmillan; 2006.

45. Addicott R, McGivern G, Ferlie E. The distortion of a managerial technique? The case of clinical networks in UK health care. $\mathrm{Br} J$ Manag. 2007;18(1):93-105

46. Abbott A. The system of professions: an essay on the division of expert labor. Chicago: The University of Chicago Press; 1988.

47. Tremblay D, Roberge D, Berbiche D. Determinants of patient-reported experience of cancer services responsiveness. BMC Health Serv Res. 2015; 15:425

48. Cloutier C, Denis JL, Langley A, Lamothe L. Agency at the managerial interface: public sector reform as institutional work. J Public Adm Res Theory. 2016;26(2):259-76.

49. Martiniuk AL, Abimbola S, Zwarenstein M. Evaluation as evolution: a Darwinian proposal for health policy and systems research. Health Res Policy Syst. 2015;13(1):15

50. Tremblay D, Roberge D, Nguyen B-L, Charlebois K, Djouder O. Perceived unmet needs of elderly cancer patients in Quebec: a descriptive study. Geriatr Oncol. 2012;3(Suppl 1):S99-100.

51. Nguyen B-L, Tremblay D, Mathieu L, Groleau D. Mixed method exploration of the medical, service-related, and emotional reasons for emergency room visits of older cancer patients. Support Care Cancer. 2016;24(6):2549-56.

52. OToole LJJ. Networks and networking: the public administrative agendas. Public Adm Rev. 2015;75(3):361-71.

53. Brault I, Denis J-L, Sullivan TJ. Using clinical governance levers to support change in a cancer care reform. J Health Organ Manag. 2015;29(4):482-97.

54. Pyone $\mathrm{T}$, Smith $\mathrm{H}$, van den Broek N. Frameworks to assess health systems governance: a systematic review. Health Policy Plan. 2017;32(5):710-22.

55. Nicholson C, Hepworth J, Burridge L, Marley J, Jackson C. Translating the elements of health governance for integrated care from theory to practice: a case study approach. Int J Integr Care. 2018;18(1):11.

56. Barbazza E, Tello JE. A review of health governance: definitions, dimensions and tools to govern. Health Policy. 2014;116:1-11.

57. Hatchuel A. Prospective et gouvernance: quelle théorie de l'action collective? In: Heurgon E, Landrieu J, editors. Prospective pour une gouvernance démocratique. Paris: Colloque de Cerisy. La Tour d'Aigues: Éditions de l'Aube; 2000. p. 29-42

58. Pomey M-P, Denis J-L, Contandriopoulos A-P. Un cadre conceptuel d'analyse de la gouvernance clinique dans les établissements de santé. Prat Organ Soins. 2008;39(3):183-94

59. Denis $J$, Champagne F, Pomey MP, Préval J, Tré G. Toward a framework for the analysis of governance in health care organizations and systems; 2005.

60. Gibson R. A primer on collaborative multi-level governance. In: A critical review of theory, practice, and potentials. Ottawa: Canadian regional development; 2011. http://cdnregdev.ruralresilience.ca/wp-content/ uploads/2013/03/primercollaborativemultilevelgovernance-gibson.pdf. Accessed 16 May 2019.

61. Touati N, Maillet $L$, Paquette M-A, Denis J-L, Rodríguez C. Understanding multilevel governance processes through complexity theory: an empirical case study of the Quebec health-care system. Int J Public Adm. 2019;42(3): 205-17.

62. Denis JL, Lamothe L, Langley A, Breton M, Gervais J, Trottier LH, et al. The reciprocal dynamics of organizing and sense-making in the implementation of major public-sector reforms. Can Public Adm. 2009;52(2):225-48.

63. Øvretveit J. Do changes to patient-provider relationships improve quality and save money? A review of the evidence about value improvements made by changing communication, collaboration and support for self-care. London: The Health Foundation; 2012. http://www.health.org.uk/sites/ health/files/

DoChangesToPatientProviderRelationshipsImproveQualityAndSaveMoney_ fullversion.pdf. Accessed 16 May 2019

64. Emerson K, Nabatchi T, Balogh S. An integrative framework for collaborative governance. J Public Adm Res Theory. 2011;22(1):1-29.

65. Levit L, Balogh E, Nass S, Ganz PA. Delivering high-quality cancer care: charting a new course for a system in crisis: National Academies Press; 2013. https://iom.nationalacademies.org/ /media/Files/Report\%20Files/2013/ Quality-Cancer-Care/qualitycancercare_rb.pdf. Accessed 16 May 2019

66. Lacoursière A. Plus d'échec que de réussites: La Presse; 2017. http://plus. lapresse.ca/screens/e1d5f21b-d81d-419d-ade8-7660ec1daef0_7C_ M8Ax833ReJRJ.html. Accessed 16 May 2019

67. Tremblay D. Mieux comprendre les réseaux en cancérologie pour les mettre en œuvre plus efficacement. In: Congrès de la Direction générale de cancérologie 2017 - Ensemble, en réseau, pour vaincre le cancer. Montréal: Ministère de la Santé et des Services sociaux; 2017. http://www.msss.gouv. qc.ca/sujets/organisation/lutte-contre-le-cancer/documents/congres_2017/ 1--Mieux-comprendre-les-reseaux-en-cancerologie-pour-les-mettre-enoeuvre-plus-efficacement.pdf. Accessed 16 May 2019.

68. Ministère de la santé et des Services sociaux (MSSS). Ensemble, en réseau, pour vaincre le cancer. In: Plan directeur en cancérologie. Québec: Gouvernement du Québec, Ministère de la Santé et des Services sociaux; 2013. http://publications.msss.gouv.qc.ca/acrobat/f/documentation/2013/13902-02W.pdf. Accessed 16 May 2019.

69. D'Amour D, Tremblay D, Bernier L. Les pratiques professionnelles de réseaux: I'intégration au-delà des structures. In: Le système sociosanitaire au Québec: gouverne, régulation et participation; 2006. p. 273-87.

70. Denis J-L, Lamothe L, Langley A, Valette A. The struggle to redefine boundaries in health care systems. In: Restructuring the professional organisation. London: Routledge; 1999. p. 105-30.

71. DiMaggio P, Powell WW. The iron cage revisited: collective rationality and institutional isomorphism in organizational fields. Am Sociol Rev. 1983;48(2):147-60.

72. Tremblay D, Touati N, Roberge D, Breton M, Roch $G$, Denis JL, et al. Understanding cancer networks better to implement them more effectively: a mixed methods multi-case study. Implement Sci. 2016;11(1):39 Tremblay2016.

73. Pawson R, Tilley N. Realist evaluation. In: Magenta Text; 2004. Accessed 16 May 2019.

74. Ministère de la santé et des Services sociaux (MSSS). Ensemble, en réseau, pour vaincre le cancer. Plan d'action 2016-2017 de la Direction générale de cancérologie. Gouvernement du Québec, Ministère de la Santé et des Services sociaux, Québec. 2016. http://publications.msss.gouv.qc.ca/msss/ fichiers/2016/16-902-07W.pdf. Accessed 16 May 2019.

75. Yin RK. Case study research: design and methods. 5th ed. Thousand Oaks: SAGE Publications; 2014.

76. Fitzgerald L, Dopson S. Comparative case study designs: their utility and development in organizational research. In: Buchanan DA, Bryman A, editors. The SAGE handbook of organizational research methods. Thousand Oaks: SAGE Publications; 2009. p. 465-83.

77. Kœnig G. Realistic evaluation and case studies: stretching the potential. Evaluation. 2009;15(1):9-30

78. Creswell J. Research design: qualitative, quantitative, and mixed methods approaches. 4th ed. Thousand Oaks: SAGE Publications; 2013.

79. Sandelowski M. "Casing" the research case study. Res Nurs Health. 2011; 34(2):153-9.

80. Doucet H. L'éthique clinique. Montréal: Les Presses de l'Université de Montréal; 2014. 
81. Canadian Institute of Health Research. Knowledge Translation at CIHR. Ottawa: Canadian Institute of Health Research; 2010. http://www.cihr-irsc.gc ca/e/29418.html. Accessed 16 May 2019

82. Cella DF, Tulsky DS, Gray G, Sarafian B, Linn E, Bonomi A, et al. The functional assessment of cancer therapy scale: development and validation of the general measure. J Clin Oncol. 1993;11(3):570-9.

83. Turner $P$, Turner S. Triangulation in practice. Virtual Reality. 2009;13(3):17181 Turner2009.

84. Redfern SJ, Norman IJ. Validity through triangulation. Nurse Res. 1994; 2(2):41-56.

85. Krueger RA, Casey MA. Focus groups: a practical guide for applied research. 4th ed. London: SAGE Publications; 2009.

86. Morse JM. Determining sample size. Thousand Oaks: SAGE Publications; 2000.

87. Guest G, Bunce A, Johnson L. How many interviews are enough? An experiment with data saturation and variability. Field Methods. 2006; 18(1):59-82.

88. Ansell C, Gash A. Collaborative governance in theory and practice. J Public Adm Res Theory. 2007;18(4):543-71.

89. Emerson K, Nabatchi T. Collaborative governance regime. Washington: Georgetown University Press; 2015.

90. Provalis Research. QDA Miner - Qualitative data analysis software. Montréal; 2019. https://provalisresearch.com/products/qualitative-data-analysissoftware/. 2019-05-15

91. Miles MB, Huberman M, Saldana J. Qualitative data analysis. A methods sourcebook. 3rd ed. Thousand Oaks: SAGE Publications; 2014.

92. Kimchi J, Polivka B, Stevenson JS. Triangulation: operational definitions. Nurs Res. 1991;40(6):364-6.

93. Gittell JH, Beswick J, Goldmann D, Wallack SS. Teamwork methods for accountable care: relational coordination and TeamSTEPPS ${ }^{\bullet}$. Health Care Manag Rev. 2015;40(2):116-25.

94. Lurie SJ, Schultz SH, Lamanna G. Assessing teamwork: a reliable fivequestion survey. Fam Med. 2011;43(10):731-4.

95. Rousseau V, Aubé C, Savoie A. Le fonctionnement interne des équipes de travail: conception et mesure. Can J Behav Sci. 2006;38(2):120-35.

96. Souza JA, Yap BJ, Wroblewski K, Blinder V, Araújo FS, Hlubocky FJ, et al. Measuring financial toxicity as a clinically relevant patient-reported outcome: the validation of the COmprehensive score for financial toxicity (COST). Cancer. 2017;123(3):476-84.

97. Valentine NB, de Silva A, Kawabata K, Darby C, Murray CJL, Evans DB. Health system responsiveness: concepts, domains and operationalization. In: Murray CJL, Evans DB, editors. Health systems performance assessment: debates, methods and empiricism. Geneva: WHO; 2003. p. 573-96.

98. van Reenen M, Janssen B. EQ-5D-5L user guide. In: Basic information on how to use the EQ-5D-5L instrument. The Netherlands: EuroQol Research Foundation; 2015. https://euroqol.org/wp-content/uploads/2016/09/EQ-5D-5 L_UserGuide_2015.pdf. Accessed 16 May 2019.

99. Sangha O, Stucki G, Liang MH, Fossel AH, Katz JN. The self-administered comorbidity questionnaire: a new method to assess comorbidity for clinical and health services research. Arthritis Rheum. 2003;49(2):156-63.

100. Longo CJ, Fitch M, Deber RB, Williams AP. Financial and family burden associated with cancer treatment in Ontario, Canada. Support Care Cancer. 2006;14(11):1077-85.

101. Martin NE, Massey L, Stowell C, Bangma C, Briganti A, Bill-Axelson A, et al. Defining a standard set of patient-centered outcomes for men with localized prostate cancer. Eur Urol. 2015;67(3):460-7.

102. Ong W, Schouwenburg MG, van Bommel AM, et al. A standard set of valuebased patient-centered outcomes for breast cancer: the international consortium for health outcomes measurement (ICHOM) initiative. JAMA Oncol. 2017;3(5):677-85.

103. Zerillo JA, Schouwenburg MG, van Bommel ACM, Stowell C, Lippa J, Bauer $D$, et al. An international collaborative standardizing a comprehensive patient-centered outcomes measurement set for colorectal cancer. JAMA Oncol. 2017:3(5):686-94.

104. Labbé C, Leung Y, Silva Lemes JG, Stewart E, Brown C, Cosio AP, et al. Realworld EQ 5D health utility scores for patients with metastatic lung cancer by molecular alteration and response to therapy. Clin Lung Cancer. 2017; 18(4):388-95.e4.

105. Gouvernement du Québec. La détresse des personnes atteintes de cancer : un incontournable de soin. In: Recommandations du Comité ad hoc sur la détection de la détresse du Comité national des cogestionnaires de la
Direction générale de cancérologie; 2017. http://publications.msss.gouv.qc. $\mathrm{ca} / \mathrm{msss} /$ fichiers/2017/17-902-11W.pdf. Accessed 16 May 2019.

106. National Comprehensive Cancer Network (NCCN). NCCN distress thermometer and problem list for patients. 2016. https://www.nccn.org/ patients/resources/life_with_cancer/pdf/nccn_distress_thermometer.pdf. Accessed 16 May 2019.

107. Watanabe SM, Nekolaichuk C, Beaumont C, Johnson L, Myers J, Strasser F. A multicenter study comparing two numerical versions of the Edmonton symptom assessment system in palliative care patients. J Pain Symptom Manag. 2011;41(2):456-68.

108. Canadian Partnership Against Cancer. Cancer partners take action to deliver person-centred cancer care. Toronto: Canadian Partnership Against Cancer; 2018. https://www.partnershipagainstcancer.ca/news-events/news/article/ cancer-partners-action-deliver-person-centred-cancer-care/. Accessed 16 May 2019

109. Boucher P, Beauregard H. Le coût économique du cancer au Québec, en 2008. Montréal: Coalition Priorité Cancer au Québec; 2010. http://www.coalitioncancer. com/documents/doc_etudePBoucher.pdf. Accessed 16 May 2019

110. Vasiliadis HM, Dionne PA, Préville M, Gentil L, Berbiche D, Latimer E. The excess healthcare costs associated with depression and anxiety in elderly living in the community. Am J Geriatr Psychiatry. 2013;21(6):536-48.

111. SPSS IBM Corp. IBM SPSS statistics for windows (version 25). Armonk: IBM Corp; 2017.

112. SAS Institute. The SAS system for Windows (version 9.4). Toronto: SAS; 2013

113. Potvin L, Di Ruggiero E, Shoveller J. Pour une science des solutions : la recherche interventionnelle en santé des populations. La santé en action. 2013;425:13-5.

114. Alla F, Kivits J. La recherche interventionnelle en santé publique : partenariat chercheurs-acteurs, interdisciplinarité et rôle social. Santé publique. 2015; 3(27):303-4.

115. Marchal B, van Belle S, van Olmen J, Hoerée T, Kegels G. Is realist evaluation keeping its promise? A review of published empirical studies in the field of health systems research. Evaluation. 2012;18(2):192-212.

116. Tremblay D. L'approche réaliste en action : le cas du travail en interdisciplinarité dans les équipes de cancérologie. In: Conférence. Montréal: Quebec network on nursing intervention research; 2016. https:// rrisiq.com/en/events/conference-tremblay-realist-approach-en. Accessed 16 May 2019.

117. Bhattacharyya O, Zwarenstein M. Methodologies to evaluate effectiveness of knowledge translation interventions. In: Knowledge translation in health care: moving from evidence to practice: Canadian Institutes of Health Research; 2015. http://www.cihr-irsc.gc.ca/e/40618.html. Accessed 16 May 2019.

118. Lomas J. Understanding evidence-based decision-making - or, why keyboards are irrational. In: Lemieux-Charles L, Champagne F, editors. Using knowledge and evidence in health care. Multidisciplinary persepctives. Toronto: University of Toronto Press; 2008.

119. Gupta A, Thorpe C, Bhattacharyya O, Zwarenstein M. Promoting development and uptake of health innovations: the Nose to Tail Tool [version 1; referees: 3 approved, 1 approved with reservations], vol. 361; 2016.

120. Lavis JN, Moynihan R, Oxman AD, Paulsen EJ. Evidence-informed health policy 4 - case descriptions of organizations that support the use of research evidence. Implement Sci. 2008;3(1):56.

121. Brown LD. The fox and the grapes: is real reform beyond reach in the United States? J Health Polit Policy Law. 2012;37(4):587-609.

122. Denis JL, Brown L, Forest PG, Normandin JM, Cambourieu C, Cannizzaro V, et al. Policy capacity for health system reform: Report submitted to the Nova Scotia Health Research Foundation; 2015. http://archives.enap.ca/ bibliotheques/2015/11/031003060.pdf Accessed 16 May 2019

123. St-Arnaud Y, Les petits groupes. Participation et animation. 3e édition ed. Montréal: Morin \& associés, Gaetan; 2008.

124. Langelier L. Travailler, apprendre et collaborer en réseau. In: Guide de mise en place et d'animation de communautés de pratique intentionnelles: CEFRIO; 2005. https://cefrio.qc.ca/media/uploader/2_travailler_apprendre_ collaborer.pdf. Accessed 16 May 2019.

125. Pope C, Ziebland S, Mays N. Analysing qualitative data. BMJ. 2000; 320(7227):114-6.

\section{Publisher's Note}

Springer Nature remains neutral with regard to jurisdictional claims in published maps and institutional affiliations. 